\title{
IDENTIFICAÇÃO DE DEFICIÊNCIAS ENTRE CRIANÇAS INDÍGENAS NAS ALDEIAS DE DOURADOS/MS
}

\author{
IDENTIFICACIÓN DE DISCAPACIDADES ENTRE NIÑOS INDÍGENAS EN LAS \\ ALDEAS DE DOURADOS/MS
}

\section{IDENTIFICATION OF DISABILITIES AMONG INDIGENOUS CHILDREN IN THE VILLAGES OF DOURADOS/MS}

\author{
Maria Goretti da Silva MATTOSO ${ }^{1}$ \\ Marilda Moraes Garcia BRUNO ${ }^{2}$ \\ Washington Cesar Shoiti NOZU ${ }^{3}$
}

RESUMO: O estudo objetivou o mapeamento de crianças indígenas com indícios de deficiências, nascidas em Dourados/MS, entre os anos de 2009 a 2014, e a avaliação da deficiência visual associada à paralisia cerebral na faixa etária de zero a cinco anos. A pesquisa pautou-se na ecologia do desenvolvimento humano e nos princípios etnográficos, contando com a participação ativa dos familiares na aplicação dos instrumentos de Avaliação Funcional da Visão integrada ao Desenvolvimento Global, cujos protocolos foram adaptados à linguagem, à cultura e ao cotidiano indígena. O mapeamento levantou o número e as condições de nascimentos das crianças indígenas, bem como a localização de cinco crianças com deficiência visual e paralisia cerebral. Por sua vez, as avalições do funcionamento visual e do desenvolvimento global permitiram identificar as necessidades específicas decorrentes da situação da deficiência e refletir sobre as estratégias para intervenção precoce, tendo em vista melhores oportunidades de aprendizagem na primeira infância.

PALAVRAS-CHAVE: Identificação de deficiências. Intervenção precoce. Educação indígena. Educação especial.

RESUMEN: Este estudio tuvo como objetivo mapear a los niños indígenas con signos de discapacidad, nacidos en Dourados/MS, entre los años de 2009 y 2014, y evaluar la discapacidad visual asociada con la parálisis cerebral en la franja etaria de cero a cinco años. La investigación está anclada en la ecología del desarrollo humano y en los principios etnográficos, y contó con la participación activa de los miembros de la familia en la aplicación de los instrumentos de la Evaluación Funcional de la Visión Integrada para el Desarrollo Global, cuyos protocolos han sido adaptados al lenguaje, a la cultura y al cotidiano de los

\footnotetext{
1 Rede Municipal de Ensino de Dourados (REME), Dourados - MS - Brasil. Mestre em Educação pela Universidade Federal da Grande Dourados (UFGD). ORCID: https://orcid.org/0000-0002-4579-4807. E-mail: mariagsm@gmail.com

${ }^{2}$ Universidade Federal da Grande Dourados (UFGD), Dourados - MS - Brasil. Docente Permanente do Programa de Pós-Graduação em Educação (PPGEdu). Doutora em Educação (UNESP). ORCID: https://orcid.org/00000002-1568-2185. E-mail: mgbruno@uol.com.br

${ }^{3}$ Universidade Federal da Grande Dourados (UFGD), Dourados - MS - Brasil. Docente Permanente dos Programas de Pós-Graduação em Educação (PPGEdu) e de Pós-Graduação em Fronteiras e Direitos Humanos (PPGFDH). Doutor em Educação (UFGD). ORCID: https://orcid.org/0000-0003-1942-0390. E-mail: wcsn1984@yahoo.com.br
} 
indígenas. El mapeo ha levantado el número y las condiciones de los nacimientos de los niños indígenas, así como la ubicación de cinco niños con discapacidad visual y parálisis cerebral. Por su turno, las evaluações del funcionamiento visual y del desarrollo global han permitido identificar las necesidades específicas derivadas de la situación de discapacidad, y reflexionar sobre las estrategias para intervención precoz, con miras a mejores oportunidades de aprendizaje en la primera infancia.

PALABRAS CLAVE: Identificación de discapacidades. Intervención precoz. Educación Indígena. Educación Especial.

ABSTRACT: This study aimed to map indigenous children with signs of disabilities, born in Dourados/MS, between 2009 and 2014, and to evaluation visual impairment associated with cerebral palsy in the age group from zero to five years. The research was based on the ecology of human development and in ethnographic principles, relying on the active participation of family members in the application of the Functional Evaluation instruments of the Integrated Vision for Global Development, whose protocols were adapted to the language, culture and indigenous daily life. The mapping surveyed the number and birth conditions of indigenous children, as well as the location of five children with visual impairment and cerebral palsy. In turn, the evaluations of visual functioning and global development made it possible to identify the specific needs arising from the disability situation and reflect on strategies for early intervention, with a view to better learning opportunities in early childhood.

KEYWORDS: Disabilities identification. Early intervention. Indigenous education. Special education.

\section{Introdução}

A identificação da condição de deficiência e das necessidades específicas em crianças, de zero a cinco anos, constitui-se em um importante procedimento para a construção de estratégias de intervenção precoce, com vistas à potencialização do desenvolvimento infantil. Entretanto, o diagnóstico de deficiência na primeira infância ainda compreende um grande desafio, sobretudo em países em desenvolvimento (ANDRADE; LEWIS, 2008; PINTO et al., 2012).

No contexto indígena, esta tarefa torna-se muito mais complexa, quer pela precarização do acesso dos povos indígenas aos serviços de Saúde e de Educação, quer pela fundamentação da deficiência em concepções mítico-religiosas das variadas etnias (SÁ, 2011; SOUZA, 2011).

À guisa de aproximação do objeto, destacam-se alguns estudos realizados com os povos Kaiowá, Guarani e Terena que habitam os municípios do sul de Mato Grosso do Sul, particularmente quanto à identificação de indígenas escolares com deficiências.

O trabalho de Bruno e Souza (2014, p. 430), sobre as representações socioculturais da deficiência entre os indígenas Guarani e Kaiowá, analisou as narrativas de líderes religiosos e 
de idosos, que sinalizaram a ausência de indígenas com deficiência no passado, "[...] ou, na pior das hipóteses, que estes eram eliminados, logo, não chegavam a se desenvolver”. Além disso, outros relatos compreendiam a causa da deficiência vinculada aos medicamentos não-indígenas e ao parto cesariano, afirmando, ainda, que era possível prevenir e tratar deficiências com remédios e rezas (BRUNO; SOUZA, 2014).

Lima (2013) apontou que os familiares de crianças indígenas surdas revelam forte sentimento de vergonha pela falta de comunicação e preocupação com o futuro de seus filhos. Coelho (2011) observou que os familiares não compreendem a surdez, pensam que as crianças surdas são "loucas" ou "cabeça fraca", não conhecem as potencialidades destas crianças e as possibilidades de comunicação e interação no ambiente familiar.

Sá e Bruno (2012) realizaram, no período de 2009-2010, em 19 escolas indígenas de 11 municípios sul-mato-grossenses, a triagem e avaliação da acuidade visual de 6.618 escolares indígenas e encontraram 210 casos de alteração de acuidade visual (erros de refração). Os escolares participantes do mapeamento cursavam os anos iniciais e finais do Ensino Fundamental, com idade entre seis e 21 anos. Esses estudantes foram encaminhados para avaliação oftalmológica em um hospital de Dourados/MS, onde foi organizado o atendimento oftalmológico com a colaboração da Fundação Nacional de Saúde (FUNASA) e das prefeituras de origem das crianças. Entre os 16 casos de deficiência visual, foram detectados nove escolares cegos e sete com baixa visão que até então não tinham sido diagnosticados. Conforme as autoras, trata-se de alta incidência, se comparada aos dados da Organização Mundial da Saúde (OMS), que indicam no Brasil, a estimativa da prevalência de cegueira de $0,062 \%$ na população até 15 anos de idade. Entre os escolares indígenas Kaiowá e Guarani estudados, a prevalência ficou em $0,15 \%$.

As autoras assinalaram que a prevalência das patologias entre os escolares indígenas foram: "atrofia óptica (seis), disfunções retinianas (quatro), coriorretinite (um), catarata congênita (um), glaucoma (um), trauma ocular (um) e alta miopia com astigmatismo (um)" (SÁ; BRUNO, 2012, p. 638).

Souza (2011, p. 126), por sua vez, identificou que, entre indígenas de aldeias dos municípios sul-mato-grossenses de Dourados e de Paranhos, a "maior incidência é de deficiência física e principalmente os casos de paralisia cerebral. Fato que pode denotar a ausência de assistência médica às gestantes e dos recursos tradicionais de acompanhamento e orientações das parteiras tradicionais". A autora elencou os fatores prováveis da paralisia cerebral entre a população indígena investigada: "desnutrição materna, desnutrição da criança, trauma de parto, anóxia perinatal (falta de oxigênio ao nascer), prematuridade, infecções 
(rubéola, toxoplasmose, pressão alta, diabetes da mãe), meningites, sarampo e traumatismos crânio encefálico" (SOUZA, 2011, p. 126).

No que tange à identificação da deficiência entre indígenas em processo de escolarização, Silva e Bruno (2016, p. 81) reiteraram que este procedimento se dá durante o Ensino Fundamental, principalmente quando o aluno apresenta dificuldades na alfabetização e na realização das operações matemáticas e, na maioria das vezes, “[...] quando a deficiência é visível".

Na revisão da produção científica, não foram localizadas pesquisas sobre a incidência de deficiência na população indígena na faixa etária de zero a cinco anos. Este dado sinaliza a importância da realização da identificação precoce da deficiência de indígenas na primeira infância, tendo em vista medidas de prevenção, atenção primária e educação dessa população.

Além disso, pesquisas apontam que a deficiência visual é uma das condições mais associadas à paralisia cerebral (REGOLIN et al., 2006; FAZZI et al., 2012), o que torna “indispensável identificar problemas e as possibilidades de facilitar o funcionamento visual dessas crianças em diferentes situações" (BRASIL, 2013, p. 29).

Neste estudo, considera-se pessoa com deficiência visual aquela que apresenta cegueira (“a acuidade visual é igual ou menor que 0,05 no melhor olho, com a melhor correção óptica") ou baixa visão (acuidade visual entre 0,3 e 0,05 no melhor olho, com a melhor correção óptica") (BRASIL, 2004).

Por sua vez, a paralisia cerebral, enquanto deficiência física (BRASIL, 2004), é definida como "um grupo de desordens permanentes do desenvolvimento do movimento e postura atribuído a um distúrbio não progressivo que ocorre durante o desenvolvimento do cérebro fetal ou infantil, podendo contribuir para limitações no perfil de funcionalidade da pessoa" (BRASIL, 2013, p. 9).

Ante o exposto, o presente texto objetiva mapear as deficiências e identificar crianças indígenas com deficiência visual e paralisia cerebral, na faixa etária entre zero a cinco anos, nas aldeias de Dourados/MS, bem como avaliar o funcionamento visual integrado ao desenvolvimento global, adequado ao contexto sociocultural indígena.

\section{Abordagem teórico-metodológica}

A construção da pesquisa percorreu os caminhos de um estudo de caso etnográfico na perspectiva socioecológica. Conforme Yin (2001, p. 21), o estudo de caso é definido como "uma investigação empírica que estuda um fenômeno contemporâneo em profundidade, em seu 
contexto de vida real, quando os limites entre o fenômeno e o contexto não são claramente evidentes". O viés etnográfico atentou-se para a compreensão do fenômeno por meio da imersão no contexto social, cultural, educacional e ecológico das crianças indígenas com deficiência.

Articuladamente, a perspectiva ecológica do desenvolvimento humano (BRONFENBRENNER, 1996), prioriza a observação do sujeito em seu ambiente natural e as interações em diferentes contextos. Bronfenbrenner (1996) usa como ilustração do ambiente ecológico as bonecas russas matryoshka, nas quais as estruturas se encaixam umas dentro das outras, simbolizando o microssistema (família, escola), o mesossistema (a criança participa de conjunto de microssistemas em inter-relações, comunidade, cultura, religião), o exossistema (a pessoa em desenvolvimento não participa dele diretamente, mas sofre as influências externas) e macrossistema (as políticas públicas e as instituições).

Particularmente, a ênfase deste estudo incidiu nas interações que ocorrem no microssistema, onde as relações cotidianas determinam o processo de desenvolvimento, e o mesossistema, contexto em que a criança indígena, na primeira infância, com ou sem deficiência, se desenvolve na família extensa, dentro da dinâmica de cada comunidade. Esses ambientes se expandem pelos serviços de saúde, na interação com os agentes de saúde, na frequência sistemática ao posto de saúde, na religiosidade da família, na escola.

Neste sentido, o estudo se propôs a analisar as interações, o funcionamento visual, integrado ao desenvolvimento global e as influências que ocorrem nos diferentes ambientes nos quais transitam as crianças indígenas com deficiência visual e paralisia cerebral. Assim, buscou atentar-se às interações na família, o impacto da atenção da Saúde e da Educação Especial para o desenvolvimento e inclusão das crianças indígenas com deficiência.

Destaca-se que, para o desenvolvimento da investigação, foram realizados todos os procedimentos éticos em pesquisa, com a devida autorização das instituições e com a assinatura de termo de consentimento livre e esclarecido pelos participantes. Os dados foram coletados no ano de 2015.

A primeira etapa consistiu em realizar o mapeamento das crianças indígenas com deficiência nascidas em Dourados/MS, no período de 2009 a 2014. Inicialmente, foram contatados os dois principais hospitais do município de Dourados/MS, responsáveis pelo atendimento à população indígena, doravante denominados de Hospital 1 e de Hospital 2, com vistas ao alcance de autorização formal para levantamento de informações sobre neonatos indígenas. A autorização para a pesquisa foi concedida somente pelo Hospital 1, cujos dados, levantados por meio de livro de registros de indígenas nascidos vivos, indicavam 11 crianças indígenas com má formação congênita, no período compreendido. 
Após esse procedimento, com o intuito de ampliar o mapeamento, contataram-se algumas instituições terapêuticas e educacionais, postos de saúde, lideranças indígenas, agentes comunitários da saúde e professores para identificação de outras crianças indígenas com possíveis deficiências nas aldeias de Dourados/MS. Nesse movimento, foram identificadas mais quatro crianças indígenas com indícios de deficiências. Assim, do total das 15 crianças indígenas, de zero a cinco anos, com suspeitas de deficiência, cinco foram selecionadas sob a hipótese de apresentarem deficiência visual e paralisia cerebral.

A segunda etapa da investigação compreendeu a avaliação do funcionamento visual integrado ao desenvolvimento global, nas cinco crianças indígenas, detectadas no mapeamento inicial. Para tanto, fez-se uso dos protocolos de Avaliação Funcional da Visão integrada ao Desenvolvimento Global, elaborados por Bruno $(2005)^{4}$, cujos instrumentos, procedimentos e materiais foram adaptados 5 à linguagem e à cultura Kaiowá e Guarani. Participaram desta etapa, os familiares, pais e/ou responsáveis das crianças indígenas com hipótese de deficiência visual e paralisia cerebral, acompanhando a aplicação dos protocolos e trazendo relatos e informações sobre seus filhos e/ou tutelados. Dentre as cinco crianças, apenas uma recebia escolarização; neste caso, também participou desta etapa da pesquisa uma professora indígena de Sala de Recursos Multifuncionais.

Conforme Bruno (2009, p. 29-30), a Avaliação Funcional da Visão e do Desenvolvimento Global recomenda:

- a mudança de foco da avaliação e da intervenção centradas na criança para uma perspectiva que reflete a ênfase na ecologia da família, do ambiente e comunidade. A crença é de que a criança se desenvolve como resultado da interação com os pais e outras pessoas no ambiente;

- a avaliação de múltiplos sistemas, isto é, da família, das interações, do ambiente, da cultura. Esses sistemas interagem e influenciam-se mutuamente e não podem ser tratados de forma isolada;

- a avaliação e intervenção centrada na família, ou seja, registros contínuos das observações e das conversações entre pais e profissionais seriam a base para as decisões acerca da intervenção;

- ênfase na conversa com a família, por meio de questionários abertos de modo a reunir informações que dirigiriam o processo de intervenção;

- atenção aos rituais familiares, às rotinas diárias e às brincadeiras que refletiriam os padrões da vida da família e seriam os meios pelos quais a intervenção seria produzida;

- além da observação das etapas de desenvolvimento da criança, utilização de uma estrutura e coleta de informações adequadas e variadas por meio de

${ }^{4}$ Para maiores informações sobre questões teóricas e metodológicas, bem como o acesso aos protocolos que constituem a referida avaliação, consultar Bruno (2005; 2009).

${ }^{5}$ Contribuíram com a adaptação dos instrumentos de avaliação duas professores indígenas e um agente de saúde indígena. 
informações sobre as interações, o desenvolvimento da criança, sobre os ambientes, os sistemas de apoio e o nível de satisfação dos pais;

- o uso de formulários de registros serviria para ajudar o professor a trabalhar com a família; obter informações ao longo do tempo sobre a criança, tais como as interações, o perfil de desenvolvimento, as percepções, os objetivos, as necessidades, as expectativas da família, e informações sobre o ambiente;

- emprego de materiais que oferecessem meios para os pais refletirem sobre as necessidades da criança, das famílias sobre recursos disponíveis e sobre suportes do ambiente.

A Avaliação Funcional da Visão integrada ao Desenvolvimento Global não vê apenas as funções visuais, observa também formas de interação, comunicação, funções perceptivas, como a criança brinca e compreende o mundo a sua volta. Esse tipo de avaliação fundamentase na teoria ecológica do desenvolvimento humano (BRONFENBRENNER, 1996), atenta ao ambiente natural da criança, por meio de relação dialógica e participação ativa da família.

Assim, a avaliação empreendida nesta etapa da pesquisa fez uso de entrevistas abertas com os familiares e de observações do desempenho visual e do desenvolvimento globais das crianças indígenas com suspeitas de deficiência visual e paralisia cerebral.

Nessa avaliação ecológica, “[...] utiliza-se para análise e interpretação dos dados de avaliação, de variáveis comunicativas de nível intrapessoal, interpessoal e grupal; variáveis situacionais, nas quais os materiais, os espaços e tempo são rearranjados no contexto natural" (BRUNO, 2009, p. 33).

A partir da observação das interações familiares e das atividades diárias foram colhidas informações sobre o funcionamento visual, de modo a compreender as possibilidades globais e as necessidades específicas que pudessem interferir no processo de aprendizagem das crianças indígenas com deficiência, de zero a cinco anos.

\section{Resultados e discussões}

Os achados deste estudo confirmam os dados de pesquisa realizada por Sá e Bruno (2012) entre a população de escolares indígenas Guarani e Kaiowá com deficiência visual, na região da Grande Dourados/MS. De forma semelhante, constatam-se indicadores de deficiências acima da média nacional entre as comunidades indígenas; a fragilidade, nos serviços de saúde indígena para gestantes, de programas de prevenção, diagnósticos, tratamento e atendimento das especialidades médicas às crianças com deficiência.

Na Reserva Indígena de Dourados (RID), cenário desta pesquisa, constituída por duas aldeias (a Bororó e a Jaguapirú), convivem indígenas das etnias Kaiowá, Guarani, Terena e o não indígena. A RID não conta com saneamento básico, coleta de lixo, manutenção das 
estradas, apresenta uma iluminação precária e falta de água. A parte vulnerável da aldeia localiza-se na região do Bororó, na qual vive a maior parte dos índios Kaiowá. Essas circunstâncias têm ocasionado alto índice de mortalidade infantil e desnutrição. Até 2005, 40\% das crianças indígenas desta região apresentavam deficiência nutricional (ALCÂNTARA, 2007).

Em algumas áreas da RID, as casas se amontoam desordenadamente, sendo que "a reunião de casas de parentes num pequeno lote costuma formar espécies de aglomerados [...]" (PEREIRA, 2007, p. 8). Como resultado "dessa nova organização, as crianças Guarani e Kaiowá têm perdido a referência da família extensa, têm ficado sem um apoio familiar firme e, quando não, inclusas nas configurações de novos casamentos" (BRUNO, 2014, p. 148). Desta forma, muitas crianças acabam ficando em situação de vulnerabilidade, em especial as crianças indígenas com deficiência (BRUNO, 2014).

Na sequência, serão apresentados dados de detecção das deficiências, bem como da Avaliação Funcional da Visão integrada ao Desenvolvimento Global, com a participação ativa dos familiares.

\section{Mapeamento de crianças indígenas kaiowá e guarani com deficiências de 0-5 Anos}

Nesse momento, será elucidada a trajetória percorrida para mapear as crianças indígenas de zero a cinco anos com má formação congênita, assim como para identificar aquelas com suspeita de possuírem deficiência visual e paralisia cerebral.

Por meio de dados obtidos junto ao Hospital 1, elaborou-se a Tabela 01, com o levantamento de crianças indígenas nascidas de 2009 a 2014 e indicativo de má formação congênita.

Tabela 01 - Registro de Neonatos Indígenas em Dourados/MS (2009 - 2014)

\begin{tabular}{c|c|c|c|c|c|c|c}
\hline Ano & $\mathbf{2 0 0 9}$ & $\mathbf{2 0 1 0}$ & $\mathbf{2 0 1 1}$ & $\mathbf{2 0 1 2}$ & $\mathbf{2 0 1 3}$ & $\mathbf{2 0 1 4}$ & Total \\
\hline Nascimentos & 217 & 176 & 260 & 134 & 124 & 62 & 973 \\
\hline Nascidos com Má Formação & 02 & 03 & 01 & 03 & 02 & 00 & 11 \\
\hline Nascimento Hospitalar & 204 & 170 & 240 & 126 & 117 & 55 & 912 \\
\hline Nascimento Domiciliar & 01 & 04 & 08 & 07 & 04 & 04 & 28 \\
\hline Nascimento em Trânsito & 12 & 02 & 12 & 01 & 03 & 03 & 33 \\
\hline
\end{tabular}

Fonte: dados da pesquisa coletados junto ao hospital 1.

Destaca-se que todos os nascimentos ocasionados nos espaços do Hospital 1 se deram mediante parto normal, já que o referido hospital não realiza cesariana. Quando o procedimento 
se faz necessário, a paciente é encaminhada ao Hospital 2 - cujos dados, como informado anteriormente, não foram acessados. O registro da ocorrência de partos variou entre o Hospital 1, em domicílio ou em trânsito.

Entre os neonatos indígenas nascidos vivos, no período de 2009-2014, o número foi de 973, sendo 11 com má formação congênita. Destas, a maior incidência entre os neonatos foi de alteração de membros (cinco), seguida de lábios leporinos e fenda palatina (três), espinha bífida (duas) e apenas uma com deficiência visual associada à paralisia cerebral. Estudos para conhecimento da etiologia das deficiências recorrentes ainda não foram realizados pelos serviços de saúde, os quais são essenciais para medidas de prevenção das deficiências.

Yamamoto (2004) assinala que é possível evitar 70\% das deficiências entre as crianças indígenas. Para tanto "a prevenção das deficiências físicas e mentais deve ser uma preocupação de toda comunidade desde antes da concepção do feto, durante a gravidez, durante o parto, pósparto imediato e ao longo de toda a vida" (YAMAMOTO, 2004, p. 53).

Os dados deste estudo revelaram: 912 nascimentos hospitalares, 28 nascimentos em domicílio e 33 nascimentos em trânsito. O número de crianças nascidas em trânsito é relevante. O nascimento em trânsito significa que a mulher entrou em trabalho de parto e a viatura da SESAI (Secretaria da Saúde Indígena), carro particular ou a carroça não chegou a tempo para encaminhar a parturiente ao hospital. O risco de sofrimento fetal é maior, pois as estradas das aldeias geralmente são esburacadas, com atoleiros e sem iluminação, sem a mínima condição para o nascimento seguro de uma criança. Assim, a criança nasce pelas mãos de familiares, do motorista ou do carroceiro, e em seguida é levada para o hospital para o término do trabalho de parto. Pelas condições do nascimento em trânsito, a criança pode sofrer anóxia neonatal (falta de oxigênio) que é uma das principais causas de deficiência visual associada à paralisia cerebral. Assim, o parto em trânsito deve ser observado pela saúde indígena como uma emergência a ser resolvida para melhor qualidade de vida às parturientes e prevenção de deficiências em neonatos.

Em posse das informações obtidas no Hospital 1, buscou-se a localização, nas aldeias da RID, das 11 crianças nascidas com má formação. A procura contou com ajuda do "capitão"6 da aldeia Bororó, de agentes de saúde, de professores e de funcionários dos postos de saúde. $\mathrm{O}$ Quadro 1 mostra a idade, a situação e a etnia das 11 crianças indígenas encontradas na RID.

${ }^{6}$ Trata-se de nomenclatura dada à liderança política da aldeia. 
Quadro 1 - Caracterização de Crianças Indígenas Nascidas com Má Formação (2009 - 2014)

\begin{tabular}{|c|c|c|c|}
\hline Criança & Idade & Situação Encontrada & Etnia \\
\hline A & 02 anos & $\begin{array}{c}\text { Má formação de membros internos compensada com o } \\
\text { crescimento. }\end{array}$ & Kaiowá \\
\hline B & 05 anos & $\begin{array}{c}\text { Espinha bífida e má formação em membro inferior, deficiência } \\
\text { física sem outras associadas. }\end{array}$ & Terena \\
\hline C & 05 anos & Lábios leporinos e fenda palatina sem cirurgia. & Kaoiwá \\
\hline D & 02 anos & Suspeita de hérnia diafragmática. & Terena \\
\hline E & 03 anos & Má formação no pé direito. & Kaiowá \\
\hline F & $\begin{array}{c}02 \text { anos e } \\
02 \text { meses }\end{array}$ & $\begin{array}{c}\text { Má formação nos membros superiores, na face e } \\
\text { comprometimentos físicos. }\end{array}$ & Kaiowá \\
\hline G & $\begin{array}{c}01 \text { ano e } \\
09 \text { meses }\end{array}$ & $\begin{array}{c}\text { Lábios leporinos e fenda palatina. A criança já fez a correção do } \\
\text { lábio leporino, mas a fenda palatina continua aberta. }\end{array}$ & Kaiowá \\
\hline H & 04 anos & $\begin{array}{c}\text { Nasceu com o "pé direito torto", fez várias cirurgias, mas não } \\
\text { resolveu o problema, sente dor no pé. }\end{array}$ & Terena \\
\hline I & $\begin{array}{c}04 \text { anos e } \\
05 \text { meses }\end{array}$ & Má formação dos dedos do pé direito. & Kaiowá \\
\hline J & 04 anos & Má formação na mão. & Kaiowá \\
\hline K & 02 anos & $\begin{array}{c}\text { Apresenta lábios leporinos e fenda palatina, já fez a cirurgia. } \\
\text { Não apresenta outras deficiências associadas. }\end{array}$ & Terena \\
\hline
\end{tabular}

Fonte: dados da pesquisa (2015).

Os dados do Quadro 01 indicam maior prevalência de má formação congênita entre crianças da etnia Kaiowá, com sete dos 11 casos. Além disso, do total das crianças encontradas, apenas uma (criança F) enquadrava-se na hipótese de deficiência visual e paralisia cerebral.

Com o intuito de ampliar o mapeamento, considerando as possibilidades de crianças indígenas nascidas no próprio domicílio, em outros hospitais ou que vieram de outras aldeias da região, foram adotadas estratégias de buscas de informações em postos de saúde, em escolas e em uma instituição especializada no atendimento de pessoas com deficiência.

Desse esforço junto às instituições e profissionais da Saúde e da Educação, foi possível identificar mais quatro crianças indígenas, entre zero e cinco anos, com hipótese de deficiência visual e paralisia cerebral. Portanto, obteve-se a amostra final de cinco crianças indígenas com o perfil eleito para a investigação.

O Quadro 2 apresenta as crianças identificadas com deficiência visual e paralisia cerebral, apresentando nome fictício, idade, etnia e formas de atendimento terapêutico e educacional. 
Quadro 2 - Crianças Indígenas, de Zero a Cinco a Anos, com Hipótese de Deficiência Visual e Paralisia Cerebral nas Aldeias de Dourados/MS

\begin{tabular}{|c|c|c|c|c|c|}
\hline $\begin{array}{c}\text { Nome } \\
\text { Fictício }^{7}\end{array}$ & Idade & Etnia & $\begin{array}{l}\text { Atendimento } \\
\text { Clínico }\end{array}$ & $\begin{array}{c}\text { Atendimento } \\
\text { Educacional } \\
\text { Especializado } \\
\end{array}$ & Escolarização \\
\hline Mitã Pora $\tilde{z}^{8}$ & $\begin{array}{c}02 \\
\text { anos }\end{array}$ & Kaiowá & Sim & Não & Não \\
\hline Mitã $i^{9}$ & $\begin{array}{c}01 \\
\text { ano }\end{array}$ & $\begin{array}{l}\text { Kaiowá/Terena } \\
\text { (mãe Kaiowá, pai } \\
\text { Terena) }\end{array}$ & Não & Não & Não \\
\hline $\begin{array}{c}\text { Mitã } \\
\text { Arandu }^{10}\end{array}$ & $\begin{array}{c}04 \\
\text { anos }\end{array}$ & Kaiowá & Sim & Não & Não \\
\hline $\begin{array}{c}\text { Mitã } \\
\text { Porayhu }^{11}\end{array}$ & $\begin{array}{c}02 \\
\text { anos }\end{array}$ & Kaiowá & Não & Não & Não \\
\hline $\begin{array}{c}\text { Mitã } \\
\text { Rory }^{12}\end{array}$ & $\begin{array}{c}05 \\
\text { anos }\end{array}$ & Kaiowá & Não & Sim & $\begin{array}{l}\text { Sim (Pré- } \\
\text { Escola) }\end{array}$ \\
\hline
\end{tabular}

Fonte: dados da pesquisa (2015).

Os dados apontam a prevalência de suspeita de deficiência visual e paralisia cerebral entre as crianças da etnia Kaiowá. Das cinco crianças identificadas, duas recebem atenção de reabilitação em uma instituição especializada, e apenas uma encontra-se em processo de escolarização com apoio de Educação Especial.

Para Bruno (2014), deve ser garantido o direito constitucional à saúde, à reabilitação e à educação para que essas crianças tenham qualidade de vida. Souza (2011) e Sá (2011) indicam que esses direitos sociais fundamentais têm sido negligenciados para as crianças indígenas em geral, com ou sem deficiência, principalmente na RID.

\section{Avaliação funcional da visão integrada ao desenvolvimento global}

Para a identificação do funcionamento da visão, os procedimentos seguiram os itens descritos por Bruno (2005) para a Avaliação Funcional da Visão. Os itens avaliados foram: reação à luz, ao brilho, ao movimento, às cores; atenção e contato visual; fixação e seguimento visual; sensibilidade aos contrastes, percepção de formas, rostos e objetos; campo visual e esfera visual.

Em relação ao Desenvolvimento Global, observou-se, também por meio de protocolo

\footnotetext{
${ }^{7}$ Os nomes, em Kaiowá e Guarani, são fictícios, elaborados acordo com as características das crianças descritas pelos familiares.

${ }^{8}$ Mitã Porã significa criança bonita.

${ }^{9}$ Mitã'i significa criancinha.

${ }^{10}$ Mitã Arandu significa criança esperta, atenta, alerta.

${ }^{11}$ Mitã Porayhu significa criança amada.

${ }^{12}$ Mitã Rory significa criança feliz/alegre.
}

Temas em Educ. e Saúde, Araraquara, v. 16, n. 1, p. 21-39, jan./jun., 2020. e-ISSN 2526-3471. 
elaborado por Bruno (2005), como a criança interage com o contexto, comunica-se e utiliza suas habilidades sensório-motoras e perceptivas para ação no meio.

Alguns dos materiais selecionados para a avaliação foram: lanterna de foco grande, copo de tereré ${ }^{13}$ com contraste branco e preto (usado pela família da criança), mamadeira da criança com contraste em branco e preto, prato, colher, bichos de plástico, cavalo, sapo, aranha, rato, boi, vaca, cachorro (animais do cotidiano indígena).

A seguir serão apresentados os resultados obtidos com a Avaliação Funcional da Visão integrada ao Desenvolvimento Global e as informações prestadas pelas famílias:

\section{a) Mitã Porã}

Nasceu em janeiro de 2013, com 36 semanas de gestação, por meio de parto normal, no Hospital 1. Em decorrência das condições de nascimento, foi internada no Hospital 2; recebeu alta com diagnóstico de prematuridade, hidrocefalia estável e paralisia cerebral. Filha de pais adolescentes, assim que recebeu alta do Hospital 2, ficou aos cuidados de um centro de recuperação nutricional, nas imediações da RID, onde permanecia internada há mais de dois anos e tinha pouco contato com a família.

Funções Visuais Básicas: a criança mostra reação às luzes, às cores, aos movimentos, às pessoas e aos rostos entre 05 e $10 \mathrm{~cm}$ de distância. Contato Visual: apresenta dificuldade para manter o contato visual, não demonstra interesse por objetos, necessita de mediação verbal para dirigir o olhar. Campo Visual: fixa o olhar no lado direito periférico e inferior. Distância Focal: a $05 \mathrm{~cm}$ é capaz de perceber o objeto. Função Viso-Motora: seguimento visual prejudicado, busca ativa dos objetos por meio do movimento e som. Função Viso-Perceptiva: a criança percebe pessoas e objetos em movimento, reconhece a mamadeira e a caneca com contraste, pelo cheiro e objetos de uso pessoal.

\section{b) Mitã'i}

Nasceu em maio de 2014, fruto de uma gestação de alto risco. A mãe, de 27 anos, entre o quarto ao sétimo mês de gestação continuou apresentando fluxo menstrual, tinha pressão alta e frequentemente estava no hospital. Aparentemente sem condições atípicas até os três meses, quando a mãe notou que ela não se desenvolvia adequadamente e foi em busca de auxílio médico em um posto de saúde na RID, por meio do qual foi encaminhada o Hospital 2, cujo

${ }^{13}$ Bebida típica do sul de Mato Grosso do Sul, elaborada com a infusão da erva-mate (Ilex paraguariensis) em água fria.

Temas em Educ. e Saúde, Araraquara, v. 16, n. 1, p. 21-39, jan./jun., 2020. e-ISSN 2526-3471. 
laudo foi indicava prematuridade, gestação de 36 semanas, com tomografia evidenciando alterações morfológicas encefálicas, sugestiva de esquizencefalia. Aos três meses de idade, Mitã' $i$ foi examinada por um oftalmologista, cujo laudo não se teve acesso. A mãe afirma que, segundo o laudo, a criança tem 100\% de visão em ambos os olhos.

Funções Visuais básicas: apresenta sensibilidade à luz, brilho, sensibilidade aos contrastes e aos objetos em uma esfera visual de $35 \mathrm{~cm}$. Mantém contato visual nessa distância. Coordenação Visual e Coordenação Olho-Objeto: apresenta interesse ao objeto próximo, na linha média inferior e mostra intenção de pegá-lo, a despeito da sua dificuldade motora. Campo Visual: localiza o objeto no campo visual inferior até $30 \mathrm{~cm}$, depois o perde. Função VisoMotora: tem segmento visual prejudicado; é incapaz de seguir os objetos por muito tempo, mas foca sua visão em objetos brilhantes e sonoros. Função Viso-Perceptiva: percebe a mamadeira e associa o uso e função do objeto; percepção pelo olfato. Reconhece o rosto da mãe e interessase pela cor e brilho de objetos usados na Avaliação Funcional da Visão. Possivelmente, tratase de deficiência visual cortical que deverá ser investigada.

\section{c) Mitã Arandu}

Nasceu em novembro de 2010, com má formação física nos pés. Aos oito meses um profissional do posto de saúde localizado na RID solicitou exames complementares porque a criança ainda não firmava o pescoço, nem se sentava. Segundo a mãe, a criança "tinha o pescoço pendurado". Foi diagnosticado com paralisia cerebral e encaminhado para uma instituição especializada de atendimento à pessoa com deficiência. O laudo médico informava sinais de displasia cortical sugerindo polimicrogiria, colpocefalia com disgenesia do corpo caloso, hipoplasia cerebelar, sinusopatia maxilar bilateral.

Funções Visuais Básicas: reage aos movimentos de pessoas, às luzes, às cores, aos rostos e aos sorrisos, mantém contato visual próximo. Apresenta fixação fugaz e campo central e periférico úteis. Função Viso-Motora: a esfera visual observada até $01 \mathrm{~m}$ faz rastreamento de objetos em movimento, mantém a fixação. Segue com a cabeça e com os olhos à luz e objetos em movimento. Função Viso-Perceptiva: identifica pessoas de perto, reconhece o cachorro, seus brinquedos, objetos familiares. Percebe gestos, mantém o interesse por imagens de livros/revistas.

\section{d) Mitã Porayhu}

Nasceu em fevereiro de 2013, durante a gravidez a mãe foi diagnosticada com diabetes e fez uso de insulina. No nascimento constatou-se uma má formação nas mãos e na orelha 
esquerda. A criança foi levada para o Hospital 2, onde obteve o diagnóstico de má formação em membro superior direito com polegar não articulado e membro superior esquerdo, má formação em pavilhão auricular bilateral.

Mitã Porayhu tem bom desenvolvimento sensório-motor, é independente, anda, corre e pula. Comunica-se com crianças e adultos. A realização da avaliação visual encontrou certos empecilhos, em razão de conflitos familiares, mas, segundo as informações da família e mediante a observação da criança brincando com uma latinha, a interação com os objetos e a exploração do ambiente, não aparenta ter deficiência visual.

\section{e) Mitã Rory}

Nasceu em julho de 2009, da etnia Kaiowá, pais falantes da língua materna, oriundos da aldeia Sucuri, em Mato Grosso do Sul. Os pais vieram para Dourados em busca de tratamento para o filho. $\mathrm{O}$ aluno está matriculado na Educação Infantil, no período vespertino, tem apoio pedagógico e frequenta a Sala de Recursos Multifuncionais, no turno contrário. A mãe relata que teve uma gestação tranquila e parto normal. Com um mês de vida a criança teve uma pneumonia, ficou internado quatro meses em uma Unidade de Terapia Intensiva (UTI). Após esses procedimentos, na opinião da mãe, o corpo dele ficou “todo mole”. Lá no hospital ficou fazendo fisioterapia nos braços e nas pernas. $\mathrm{O}$ médico disse que ele não tinha mais chance de vida, pois ele só respirava com ajuda de aparelhos. Contrariando as expectativas, se desenvolveu e começou a andar com dois anos de idade. Com três anos só falava as iniciais das palavras. Os pais disseram que ele é alegre, agitado, contudo, inconstante no humor e se irrita facilmente.

Conforme relata a professora da Sala de Recursos Multifuncionais, Mitã Rory apresenta alteração motora do lado esquerdo, dificuldades de concentração e atenção, oscilações comportamentais e emocionais. Ainda, relata que a criança tem dificuldade visual: coloca os objetos bem próximos de si para enxergar; precisa de ajuda para pegar na colher e incentivo para comer. Além disso, gosta muito de jogar bola e de manusear livros com figuras, principalmente os que contêm figuras de animais.

Funções Visuais Básicas e Viso-Motoras: apresenta sensibilidade aos contrastes; reage ao movimento de pessoas, à luz próxima, aos rostos, sorrisos de pessoas conhecidas. O contato visual em relação aos objetos muitas vezes é rápido, em outros, momentos, o olhar é distante e desligado. Reage a objetos com brilho e alto contraste quando próximo, cerca de $30 \mathrm{~cm}$ de distância. Mostrou dificuldade para fixação e manutenção do contato visual com objetos em posição central. Prefere brincar deitado de lado para facilitar a fixação e a identificação dos 
mesmos. O seguimento visual mostrou-se prejudicado, apresenta movimentos involuntários (nistagmo) e evidencia o estrabismo. Busca objeto em movimento e pelo som. Campo visual alterado.

As crianças indígenas avaliadas, com exceção de Mitã Porayhu, apresentaram sintomas, sinais e resposta visual compatíveis com baixa visão, perda acentuada da função visual, restrição de campo visual e esfera visual bastante prejudicada. Como não competia a esta pesquisa realizar diagnóstico oftalmológico, orientou-se o encaminhamento das crianças ao Hospital 2, que é o responsável pelo atendimento de especialidades médicas aos povos indígenas no município de Dourados/MS, para avaliação oftalmológica e das possíveis necessidades de correção óptica. Deve ser investigada ainda a possível indicação de recursos ópticos especiais para atividades escolares do aluno em processo de escolarização.

Foram realizadas, para as famílias e cuidadores, orientações sobre estratégias de intervenção precoce para estimulação visual integrada ao desenvolvimento global das crianças. Cabe pontuar que apenas uma criança frequenta a Educação Infantil, para esta, foi elaborado, em conjunto com a professora especialista da Sala de Recursos Multifuncionais, um Plano de Atendimento Educacional Especializado e de atividades pedagógicas para a otimização da visão residual, desenvolvimento das funções viso-motoras e perceptivas, da autonomia e independência, bem como orientações para atendimento de necessidades específicas no contexto da sala regular. Estas atividades foram disponibilizadas junto à unidade escolar na qual o aluno encontrava-se matriculado.

\section{Considerações finais}

O mapeamento de crianças indígenas Kaiowá e Guarani com má formação congênita, no período de 2009-2014, em Dourados/MS revelou: 912 nascimentos em hospitais, 28 em domicílios e 33 nascimentos em trânsito ocorridos durante o transporte até o hospital. Cabe destacar, neste último caso, o número expressivo e as condições de alto risco das parturientes que podem ser fatores responsáveis pela anóxia neonatal, a maior causa de deficiência visual e paralisia cerebral, entre neonatos. Estamos, assim, diante de um quadro de produção da deficiência.

O levantamento inicial apontou 11 crianças nascidas com má formação congênita no período, observando-se a prevalência de: alterações nos membros inferiores e superiores (cinco), lábios leporinos e fenda palatina (três) e outras alterações orgânicas (três), dentre as quais, uma com hipótese de deficiência visual e paralisia cerebral. Tais dados apontam a 
necessidade de investigações clínicas acerca da etiologia que desenvolve alterações nos neonatos.

O contato com instituições educacionais e de reabilitação, bem como com profissionais da Saúde e da Educação, tornaram possível a identificação de mais quatro crianças, de zero a cinco anos, nas aldeias indígenas de Dourados/MS, com suspeita de deficiência visual associada à paralisia cerebral.

Os resultados das Avaliações Funcionais da Visão integrada ao Desenvolvimento Global indicam que das cinco crianças, quatro apresentam baixa visão significativa com: resposta visual entre $10 \mathrm{~cm}$ e $1 \mathrm{~m}$ de distância, alteração da motilidade ocular, desvio ocular, dificuldade de fixação e seguimento visual e alterações viso-perceptivas. Torna-se emergencial que estas crianças sejam encaminhadas para avaliação oftalmológica, correção das possíveis alterações oculares, a programas de intervenção precoce; e para o aluno em escolarização, a investigação de recursos ópticos especiais para otimização da aprendizagem.

Cabe destacar que o direito das crianças com deficiência aos programas de detecção e intervenção precoce é assegurado pela Lei Brasileira de Inclusão (BRASIL, 2015) e pela Política Nacional de Educação Especial na perspectiva da Educação Inclusiva (BRASIL, 2008). Os referidos documentos recomendam ações intersetoriais no campo da Saúde, Educação e Assistência social, tendo em vista o atendimento à criança e a orientação às famílias.

Bronfenbrenner (1996) ajuda a entender as relações que se estabelecem entre os vários ambientes em que a pessoa em desenvolvimento está inserida e a influência sobre o processo de aprendizagem e a qualidade de vida. No caso da população indígena, a omissão das políticas públicas quanto à prevenção das deficiências e a atenção primária às crianças têm sido responsáveis pela situação de vulnerabilidade vivida pelas crianças indígenas com deficiência na região da Grande Dourados.

A trajetória da presente investigação pautou-se na ação colaborativa junto às famílias, atentando-se aos diálogos interculturais necessários, e na elaboração conjunta com a professora especialista da Sala de Recursos Multifuncionais de um Plano de Atendimento Educacional Especializado, possibilitando à comunidade escolar o conhecimento das necessidades específicas do aluno e, com isso, as adequações para a sala de aula.

Além disso, este estudo abre uma fenda para a discussão sobre a fragilidade dos direitos das crianças indígenas com deficiência, com ações no âmbito da Saúde para a prevenção de deficiências secundárias e abre oportunidade para a criação de um programa de intervenção precoce centrado na família e na comunidade indígena, que seja fundado nos valores e nas culturas das etnias envolvidas. 
Espera-se que, em momento tão incerto para as crianças que nascem sob o ciclo de epidemia da dengue, Chicungunya e Zika vírus, fatores que podem ocasionar casos de partos prematuros e de microcefalia, as famílias possam ter esperança de melhores oportunidades de desenvolvimento, aprendizagem e qualidade de vida, dentro do modo de ser indígena.

\section{REFERÊNCIAS}

ALCÂNTARA, M. L. B. Jovens indígenas e lugares de pertencimento: análise dos jovens indígenas da reserva de Dourados/MS. São Paulo: Instituto de Psicologia da Universidade de São Paulo; Laboratório de Estudos do Imaginário, 2007.

ANDRADE, I. F. C.; LEWIS, D. R. A negligência mundial sobre a deficiência auditiva infantil em países em desenvolvimento. Distúrbios da Comunicação, São Paulo, v. 20, n. 2, p. 279-281, ago. 2008. Disponível em:

https://revistas.pucsp.br/index.php/dic/article/view/6825/4944. Acesso em: 24 mar. 2020.

BRASIL. Decreto n. 5.296 de 2 de dezembro de 2004. Brasília, DF: Presidência da República, 2004.

BRASIL. Ministério da Educação. Política nacional de educação especial na perspectiva da educação inclusiva. Brasília, DF: MEC/SEESP, 2008.

BRASIL. Ministério da Saúde. Diretrizes de atenção à pessoa com paralisia cerebral. Brasília, DF: Ministério da Saúde, 2013.

BRASIL. Lei n. 13.146 de 6 de julho de 2015. Institui a Lei Brasileira de Inclusão da Pessoa com Deficiência (Estatuto da Pessoa com Deficiência). Brasília, DF: Congresso Nacional, 2015.

BRONFENBRENNER, U. A ecologia do desenvolvimento humano: experimentos naturais e planejados. Porto Alegre: Artes Médicas, 1996.

BRUNO, M. M. G. Avaliação educacional de alunos com baixa visão e múltipla na educação infantil: uma proposta de adaptação e elaboração de instrumentos. 2005. $240 \mathrm{f}$. Tese (Doutorado em Educação) - Universidade Estadual Paulista Júlio de Mesquita Filho, Marília, 2005.

BRUNO, M. M. G. Avaliação educacional de alunos com baixa visão e múltipla deficiência na educação infantil. Dourados: Editora da UFGD, 2009.

BRUNO, M. M. G. A pessoa com deficiência na cultura Guarani-Kaiowá: o que dizem as pesquisas. In: MENDES, E. G.; CIA, F. (Orgs.). Inclusão escolar e o atendimento educacional. São Carlos: Marquezine \& Manzini; ABPEE, p. 145-159, 2014.

BRUNO, M. M. G.; SOUZA, V. P. S. Crianças indígenas Kaiowá e Guarani: um estudo sobre as representações da deficiência. Revista Educação Pública, Cuiabá, v. 23, n. 53/1, p. 425440, maio/ago. 2014. Disponível em: 
http://periodicoscientificos.ufmt.br/ojs/index.php/educacaopublica/article/view/1626/1253.

Acesso em: 20 mar. 2020.

\section{COELHO, L. L. A constituição do sujeito surdo na cultura Guarani- Kaiowá: os}

processos próprios de interação e comunicação na família e na escola. 2011. $125 \mathrm{f}$.

Dissertação (Mestrado em Educação) - Universidade Federal da Grande Dourados, Dourados, 2011.

FAZZI, E. et al. Neuro-ophthalmological disorders in cerebral palsy: ophthalmological, oculomotor, and visual aspects. Developmental Medicine and Child Neurology, v. 54, n. 8, p. 730-736, 2012.

LIMA, J. M. S. A criança indígena surda na cultura Guarani-Kaiowá: um estudo sobre as formas de comunicação e inclusão na família e na escola. 2013. 214 f. Dissertação (Mestrado em Educação) - Universidade Federal da Grande Dourados, Dourados, 2013.

PEREIRA, L. M. A atuação do órgão indigenista oficial brasileiro e a produção do cenário multiétnico da Reserva Indígena de Dourados, MS. In: ENCONTRO ANUAL DA ANPOCS, 38., 2014, Caxambu. Anais [...]. Caxambu, 2014. Disponível em:

http://www.anpocs.com/index.php/encontros/papers/38-encontro-anual-da-anpocs/gt-1/gt211/8809-a-atuacao-do-orgao-indigenista-oficial-brasileiro-e-a-producao-do-cenariomultietnico-da-reserva-indigena-de-dourados-ms. Acesso em: 15 mar. 2020.

PINTO, M. M. et al. Idade no diagnóstico e no início da intervenção de crianças deficientes auditivas em um serviço público de saúde auditiva brasileiro. Arquivos Internacionais de Otorrinolaringologia, São Paulo, v. 16, n. 1, p. 44-49, jan./mar. 2012. Disponível em: http://www.scielo.br/pdf/aio/v16n1/06.pdf. Acesso em: 26 mar. 2020.

REGOLIN, K. et al. Avaliação da função visual em crianças com paralisia cerebral tipo tetraparesia e diparesia espástica: apresentação de um instrumento em terapia ocupacional. Temas sobre Desenvolvimento, São Paulo, v. 15, v. 85-86, p. 24-29, 2006.

SÁ, M. A. O escolar indígena com deficiência visual na região da Grande Dourados-MS: um estudo sobre a efetivação do direito à educação. 2011. 155 f. Dissertação (Mestrado em Educação) - Universidade Federal da Grande Dourados, Dourados, 2011.

SÁ, M. A.; BRUNO, M. M. G. Deficiência visual nas crianças indígenas em idade escolar das etnias Guarani e Kaiowá na região da Grande Dourados/MS: um estudo sobre a incidência e as necessidades específicas e educacionais especiais. Revista Brasileira de Educação Especial, Marília, v. 18, n. 4, p. 629-646, out./dez. 2012. Disponível em: http://www.scielo.br/pdf/rbee/v18n4/a07v18n4.pdf. Acesso em: 15 fev. 2020.

SILVA, J. H.; BRUNO, M. M. G. A avaliação das necessidades específicas e educacionais de crianças indígenas com deficiência da Terra Indígena de Dourados/MS. Revista Teoria e Prática da Educação, v. 19, n.1, p. 77-88, jan./abr. 2016. Disponível em: http://periodicos.uem.br/ojs/index.php/TeorPratEduc/article/view/29081. Acesso em: 10 fev. 2020.

SOUZA, V. P. S. Crianças Kaiowá e Guarani: um estudo das representações sociais sobre deficiência e sobre o acesso às políticas de saúde e educação em aldeias da região da Grande 
Dourados. 2011. 173 f. Dissertação (Mestrado em Educação) - Universidade Federal da Grande Dourados, Dourados, 2011.

YAMAMOTO, R. M. Manual de atenção à saúde da criança indígena brasileira. Brasília, DF: Fundação Nacional de Saúde, 2004.

YIN, R. K. Estudo de caso: planejamento e métodos. 2. ed. Porto Alegre: Bookman, 2001.

\section{Como referenciar este artigo}

MATTOSO, Maria Goretti da Silva; BRUNO, Marilda Moraes Garcia; NOZU, Washington Cesar Shoiti. Identificação de deficiências entre crianças indígenas nas aldeias de Dourados/MS. Temas em Educ. e Saúde, Araraquara, v. 16, n. 1, p. 21-39, jan./jun., 2020. eISSN 2526-3471. DOI: https://doi.org/10.26673/tes.v16i1.13503

Submetido em: 03/02/2020

Revisões requeridas: 20/04/2020

Aprovado em: 06/06/2020

Publicado em: 19/06/2020 